\title{
PSICOANÁLISIS DE LA OBRA DE FRIDA KAHLO
}

\section{Psychoanalysis of Frida Kahlo's work}

\author{
Carmen Morales Miranda*
}

\begin{abstract}
Resumen
La investigación psicoanalítica de la obra de alguna figura de la humanidad (Frida Kahlo en el presente ensayo) no persigue, ciertamente, los fines que con tanta frecuencia le son atribuidos, es decir "oscurecer lo radiante y derribar lo elevado" en el artista, todo lo contrario, su única motivación es el extraordinario interés por todo aquello que tales modelos puedan descubrirle. Es posible que luego de haber leído su biografía se considere que las situaciones tan penosas (la poliomielitis y el accidente) por las que atravesó Frida, sean los causantes del contenido de su obra. Si así fuera ¿qué hizo que aquellas situaciones se tornaran tan traumáticas?

El análisis se basa sólo en las descripciones biográficas de la autora, el contenido de sus escritos (poemas) y de sus cuadros pintados. Al analizar la obra de Frida Kahlo encontramos 3 temas, que aparte de ser recurrentes en su obra, es inevitable someterlos al análisis para poder entender la personalidad y la creación de la artista. Nos referimos a la masturbación, la homosexualidad y la maternidad.
\end{abstract}

Palabras clave: Psicoanálisis, Frida Kahlo.

\begin{abstract}
The psychoanalytic investigation of the work of an importantpersonality(Frida Kahlo in this essay) does not have the purposes that so often are attributed to an artist, that is to say "to dim radiance and to demolish constructions." On the contrary, its only motivation is the extraordinary interest in all that can be discovered by such models. After reading her biography, such painful situations (poliomyelitis and accident) that Frida experienced are likely to be considered the reasonforthe content of her work. If this were the case, what turnedthose situations so traumatic?

The analysis is based only on the author's biographical description, the content of her writings (poems) and her paintings. Whenanalyzing Frida Kahlo's work, we find 3 topics whichbesidesbeing recurrent in her work-need to be analyzed in order to understand the artist's personality and creation. We imply masturbation, homosexuality and motherhood.
\end{abstract}

Keywords: Psychoanalysis, Frida Kahlo

\footnotetext{
* Psicoterapeuta Psicoanalítica. Docente de la Universidad Femenina del Sagrado Corazón y del Centro de Psicoterapia Psicoanalítica de Lima - CPPL.cmdei@speedy.com.pe
} 


\section{BIOGRAFÍA DE FRIDA KAHLO}

Frida Kahlo, nace en Coyoacán, Distrito Federal de México, en el año de 1907. Fue hija del destacado fotógrafo alemán Guillermo Kahlo Kauffman y doña Matilde Calderón. Cuando apenas tenía 2 meses de nacida su madre volvió a gestar. Once meses después de su nacimiento nació su hermana Cristina. Frida fue confiada a una nana india ${ }^{1}$, hecho que la marcó mucho, convirtiéndola, en la encarnación de la herencia mexicana, algo de lo que siempre se enorgulleció (influencia que se aprecia en cuanto a los colores y los elementos, utilizados en muchos de sus cuadros). En 1937, dejó constancia de ello en su obra "Mi nana y yo" y en "Yo mamando". Este hecho hizo que Frida no se sintiera unida a su madre, a quien calificaba como activa, inteligente, pero también calculadora, cruel y fanáticamente religiosa. A los 6 años padece de poliomielitis y, como secuela, la pierna derecha le queda más corta y delgada, y el pie derecho ligeramente deformado, por lo que sufre la burla de la gente. En 1922 Frida ingresó a la Escuela Nacional Preparatoria con la intención de encauzar sus estudios hacia la Medicina.

A los 18 años, sufrió un accidente viajando en ómnibus de Coyoacán al centro de la ciudad, el cual le ocasionó, once fracturas y el espectáculo de un cuerpo ensangrentado bañado en purpurina dorada, transportada en el mismo autobús en que iba. Su padre la acompañó en la convalecencia, obsequiándole material para que pintara, y se acompañara durante los largos periodos de tratamientos e intervenciones quirúrgicas que padeció. Comenzó a pintar, durante una larga convalecencia (obligada a ingerir fuertes medicamentos cuyo fin era evitar las intensas sensaciones de dolor), copiando su rostro de un espejo montado en el dosel de la cama.

Cuando Frida cursaba estudios en la Preparatoria conoce a Diego Rivera en el auditorio de su escuela, donde el artista debía pintar un mural por encargo del gobierno. Frida y Diego se casaron en 1929 y ella siempre tuvo la obsesión de tener un hijo (lo cual era imposible debido a las secuelas del accidente), lo intentó más de una vez, con resultados trágicos poniendo en riesgo su propia vida. La vida sentimental de ambos fue tortuosa y variada, tanto uno como otro permitían relaciones extra conyugales.

En cuanto a su obra (influida por la de su marido), empleó las zonas de color amplias y sencillas plasmadas en un estilo deliberadamente ingenuo. Al igual que Rivera, quería que su obra fuera una afirmación de su identidad mexicana y por ello, recurría con frecuencia a técnicas y temas extraídos del folclore y del arte popular de su país. Más adelante, la inclusión de elementos fantásticos, claramente introspectivos, la libre utilización del espacio pictórico y la yuxtaposición de objetos incongruentes, realzaron el impacto de su obra, llegando a ser relacionada con el movimiento surrealista. Y es, mediante una infinidad de autorretratos que quiere expresarse, manifestar sus diferentes estados de ánimo, mostrando las distintas etapas por las que atravesó.

En los últimos años de su vida, sin ser escritora, Frida se dispone a volcar sus impresiones en papel y nace así su "Diario: Autorretrato íntimo", oculto y privado. La salud de Frida la obligó a impartir clases de pintura en su propia casa, donde los alumnos circulaban libremente mientras ella les estimulaba a pintar lo que veían. Frida tenía cada vez menos esperanzas de recuperar su preciada salud, refugiándose en el alcohol y la pintura. Los médicos diagnosticaron una embolia pulmonar, cuando al amanecer del 13 de julio de 1954, la encontraron muerta en su cama. La última frase de su diario, abruptamente interrumpida por su muerte, dice: "Espero alegre la salida y espero no volver jamás.".

\section{PSICOANÁLISIS DE SU OBRA}

La investigación psicoanalítica de la obra de alguna figura de la humanidad (Frida Kahlo en el presente ensayo), no persigue, ciertamente, los fines que con tanta frecuencia le son atribuidos, es decir "oscurecer lo radiante y derribar lo elevado" en el artista, todo lo contrario, su única motivación es el extraordinario interés por todo aquello que tales

1. En una charla que Frida mantuvo con la periodista Raquel Tibol le dijo al respecto: "Mi madre no me pudo amamantar porque a los once meses de nacer yo, nació mi hermana Cristina. Me alimentó una nana a quién lavaban los pechos cada vez que yo iba a succionarlos". 
modelos puedan descubrirle. Freud afirma que el hallarse sometido a aquellas leyes que rigen, tanto el análisis de la actividad normal, como la patológica, no debe producir vergüenza. Todo lo contrario, tampoco debe dejar de analizarse lo que muchas veces se obvia de las biografías, y que, en psicoanálisis consideramos de vital importancia, pues si "se quiere llegar realmente a una profunda comprensión de la vida anímica del sujeto investigado, no se debe silenciar por discreción o hipocresía, lo que hacen la mayor parte de los biógrafos, las características sexuales de la vida del mismo" (Freud, 1910, pág. 1581).

Para Joyce McDougall (1992, pág. 102), la creatividad se origina en el cuerpo erógeno, reflejando la manera como se representa psíquicamente y como las funciones somáticas han sido estructuradas en la infancia. Los individuos creativos, se enfrentan con partes fragmentadas de ellos mismos, y al mismo tiempo, tratan febrilmente de mantener su sentimiento de cohesión e identidad subjetiva a través de su obra o invención.

¿Acaso sería la tristeza que siente, por las situaciones que ha tenido que vivir: la burla de la gente por padecer poliomielitis, las secuelas de su accidente en el autobús, la incapacidad para tener hijos, las múltiples infidelidades de las que su esposo la hizo objeto hasta con su propia hermana?

Si nos ceñimos al estricto análisis del lenguaje corporal, nos queda claro que por sus autorretratos, en los que nos deja apreciar su absoluta desconfianza, inferida de su mirada autosuficiente, de la elevación de sus cejas que se muestran amenazadoras, de sus labios apretados con intensidad y de la notoria presión y rigidez de su garganta.

En cuanto a la motivación de su obra, tenemos a una artista que nos dice: "Pinto mi propia realidad. Lo que sé es que pinto porque necesito hacerlo, y siempre pinto lo que me entre en la cabeza sin ninguna otra consideración". Para Frida, la creación artística, no parece significar otra cosa, que la descarga de sus sentimientos y emociones; especialmente aquellas que la atormentan. Esta situación, es suficiente para descartar que su obra sea producto de la sublimación, ya que esta última es un proceso que implica más elaboración y no la simple catarsis o descarga emocional.

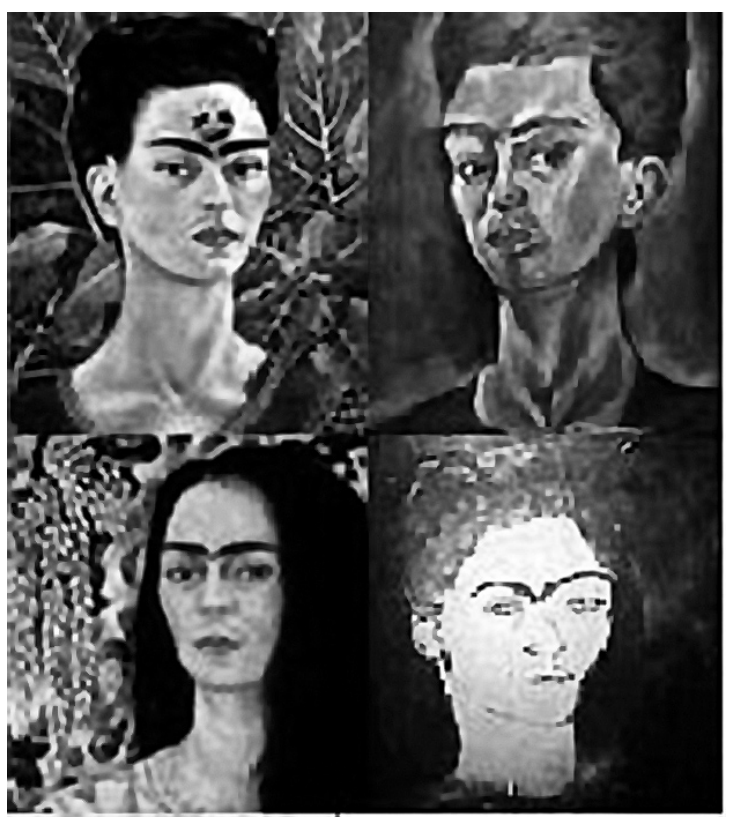

Los rostros de los autorretratos de Frida

\section{TRAUMA PSÍQUICO}

Es posible que, luego de haber leído su biografía, se considere que las situaciones tan penosas (la poliomielitis y el accidente) por las que atravesó Frida, sean los causantes del contenido de su obra. Si así fuera ¿qué hizo que aquellas situaciones se tornaran tan traumáticas?.

Sabemos, que el traumatismo psíquico, fue considerado, inicialmente por Freud, como un acontecimiento inmediatamente anterior a la instalación del síntoma, o coetáneo de éste. Posteriormente, Freud se vio impulsado a reconocer que el carácter traumático no se vinculaba al acontecimiento como tal, sino a la

2. Joyce Mc Dougall (1992) menciona el análisis de una artista la cual describe la motivación de sus creaciones de forma muy parecida a la de Frida: "Las tendencias profundas y esenciales que me habitan se vuelven lo bastante fuertes como para incomodarme; tengo que expulsar la tensión que experimento, para que pueda instalarse en mí una forma de armonía: es la creación”. 
significación que la persona hiciera de éste, el cual siempre se trataba, de hecho, de la reviviscencia de un recuerdo penoso, o de un traumatismo psíquico de la infancia ${ }^{3}$. Es por esta afirmación que se puede entender por qué algunas personas sufren trastornos ante hechos "traumáticos" mientras que otras, ante los mismos, no lo hacen. Lo que, en último caso, sí se le puede atribuir a la situación traumática es, que la irrupción de energía acaecida en el individuo provoca la reactivación de antiguos conflictos, que persisten en estado latente mientras el sujeto dispone de bastante energía para mantener la represión, pero, una vez desbordada, es capaz de alterar la vida psíquica del individuo, e incluso la fisiológica, produciéndole serios trastornos.

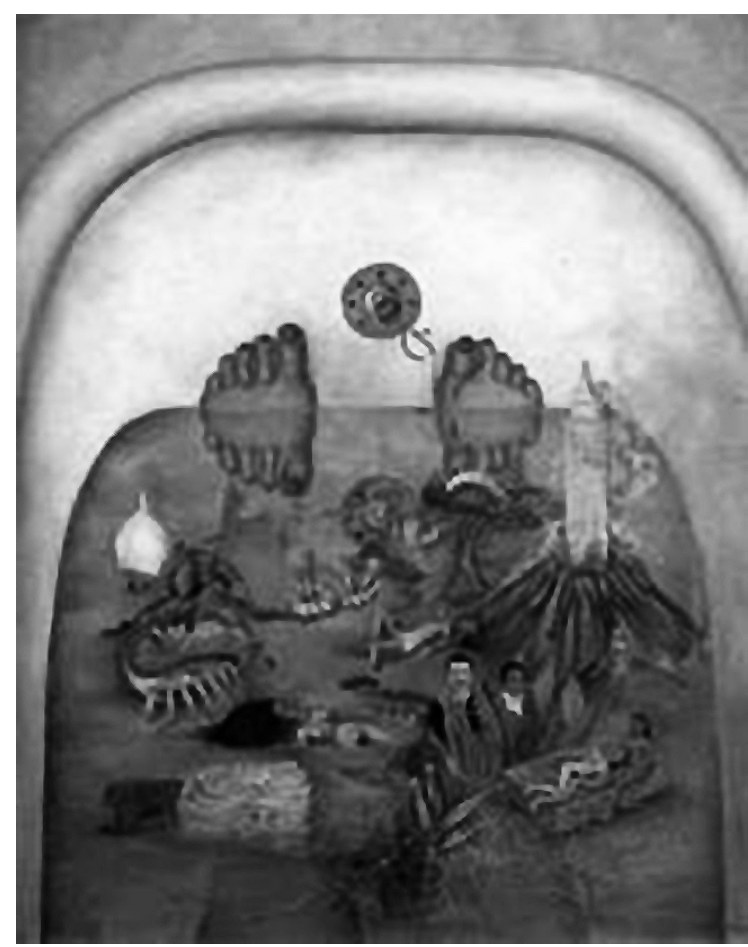

Lo que vi

Este cuadro parece representar todo aquello que en su vida tuvo relevancia: sus pies deformados por la poliomielitis, la homosexualidad, la relación entre sus padres, el simbolismo sexual de los genitales representados por el cráter y la torre que se erige en él y su maternidad frustrada a través de aquello que parece representar una cuna con un bebé en él.
Al analizar la obra de Frida Kahlo encontramos 3 temas, que aparte de ser recurrentes en su obra, es inevitable someterlos al análisis para poder entender la personalidad y la creación de la artista. Nos referimos a la masturbación, la homosexualidad y la maternidad.

\section{Masturbación}

¿Que podría significar la poliomielitis que convirtió a la niña alegre y traviesa en introvertida y que la llevó también a construir la fantasía de una amiga imaginaria, de la cual hablaría más tarde en su diario para explicar el origen de Las dos Fridas?

En primer lugar, la literatura psicoanalítica ha demostrado, fehacientemente, que las actitudes parentales influyen en las sensaciones de bienestar o malestar de los niños. Si esas acciones son negativas, producen inseguridad, culpa, rechazo, etc., convirtiéndose en posibles factores relevantes, para el establecimiento de las neurosis. Así, del análisis de sus pacientes mujeres, McDougall (1992) pudo concluir que, "muchas de las representaciones corporales inconscientes que la mujer tiene de sí misma dependen de la manera en que su propia madre invistió, en términos libidinales y narcisistas, su sí mismo físico y psíquico, y también de lo que la madre le trasmitió de sus propias ansiedades inconscientes acerca de sus funciones corporales y sexuales".

En segundo lugar, sabemos que los niños experimentan curiosidad desde la más tierna edad y la autoexploración de zonas que le producen placer. Del análisis de las neurosis, se ha llegado a afirmar que, aunque la masturbación, es la expresión normal de la sexualidad infantil, esta puede ser contrarrestada por las coacciones parentales ${ }^{4}$, aumentando el riesgo de que los niños sufran problemas neuróticos, y padezcan de una imagen corporal deteriorada y frágil.

Por tanto, imaginemos la vida de Frida, donde su madre -descrita por ella misma como, "una persona distante, fría, calculadora y fanáticamente religiosa"la haya observado con esa curiosidad por tocarse. $\mathrm{Si}$ consideramos la característica de su persona, definida

3. Véase Estudios sobre la histeria (1895).

4. Es decir, los progenitores tratan de controlar sus propias angustias a través del control sexual constante y severo de sus hijos. 
como "fanáticamente religiosa", lo más lógico de pensar es que, al descubrirla la haya amenazado constantemente, calificando la masturbación como: "pecado que será castigado"s.

La misma Frida parece darfe de esta interpretación, a través de un poema, expresando aquella situación prohibida por su madre:

Ya llega mi mano, mi roja visión.

Más grande, más suya,

martirio del vidrio, la gran sinrazón.

Columnas y valles

Los dedos del viento,

los niños sangrantes, la mica micrón.

No se lo que piensa mi sueño burlón.

La tinta, la mancha, la forma, el color.

Soy ave. Soy todo. Sin más turbación.

Así, parece probable que Frida consideró la poliomielitis como un castigo por masturbarse, pues, coincidentemente con la aparición de la enfermedad, experimentó un "desdoblamiento" de su personalidad" el cual es muy frecuente cuando se sufre un intenso conflicto entre un placer prohibido y un miedo emergente al castigo o a la muerte. Es probable, que Frida sintiera tanta culpa por la "masturbación placentera" que, para aplacar en sí misma esa angustia, tuvo que crear aquella amiga imaginaria, la cual no era presa de ninguna culpa, tan libre como la naturaleza, una amiga que disfrutaba de esa libertad de la que ella no gozaba pero que, gracias a este desdoblamiento, pudo hacerlo "sin culpa”, y de quien se expresaba así:

“... No recuerdo su imagen ni su color.

Pero si se que era alegre - se reía mucho.
Sin sonidos. Era ágil. y bailaba como si no tuviera peso ninguno”.

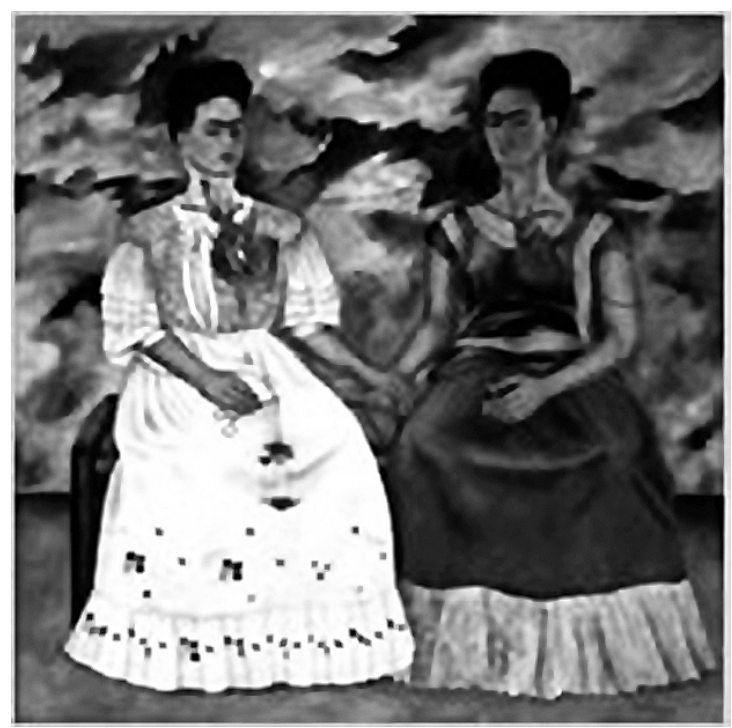

Las dos Fridas (1939)

Un retrato en el que se representa el desdoblamiento de la personalidad que Frida sufrió a la edad de 6 años. En uno está representada la Frida con el traje blanco "puro", con ropa que la cubre y que la hace ver como aquella mujer, "santa" y recatada. En cambio la otra Frida, se aprecia como alguien más atrevida con ropa mucho más ligera, más suelta. Pero sin duda las dos en el mismo mundo, representado por un fondo de colores $y$ formas tan turbias, como su vida desde aquellos años.

\section{Homosexualidad}

Otra cuestión que se manifiesta reiteradamente en su obra es la homosexualidad. McDougall (1992) nos dice respecto al arte creativo que, "el placer que procuran las actividades artísticas y profesionales está impregnado de fantasmas narcisistas y homosexuales, en la medida en que, en el proceso creativo, se es al mismo tiempo hombre y mujer".

5. Según McDougall (1992): "Los conflictos derivados de las angustias y deseos inconscientes de los progenitores pueden contribuir a la construcción de una imagen corporal deteriorada y frágil. Además si esta imagen es reforzada por un discurso parental que denigra y hace amenazador todo lo que concierne a la sexualidad, el problema de la imagen narcisista es inmediatamente desplazado sobre el sí mismo sexual y en el caso de las mujeres sobre lo vinculado a la noción de feminidad" (McDougall, 1992)

6. La propia Frida nos dice: "Debo haber tenido seis años cuando viví intensamente la amistad imaginaria con una niña de mi misma edad o menos. En la vidriera del que entonces era mi cuarto y que daba a la calle de Allende. Sobre uno de los primeros cristales de la ventana echaba vaho y con el dedo dibujaba "puerta". Por esa "puerta", salía en la imaginación, con gran alegría y urgencia. Atravesaba todo el llano que se miraba, hasta llegar a una lechería que se llamaba "PINZÓN"... Por la "O" de PINZÓN entraba y bajaba impetuosamente al interior de la tierra, donde "mi amiga imaginaria" me esperaba siempre.(...) era alegre, se reía mucho, sin sonidos era ágil y bailaba como si no tuviera peso alguno. Yo la seguía en todos sus movimientos y le contaba, mientras ella bailaba , mis problemas secretos (...) yo era feliz (...) Han pasado 34 años desde que viví esa amistad mágica y cada vez que la recuerdo, se aviva y se acrecienta más y más dentro de mis mundos". 
¿Cuál es el origen de la homosexualidad que se evidencia en la obra de Frida Kahlo?. Encontramos la respuesta en la literatura psicoanalítica, ya que son muchas las obras cuyo tema de investigación ha sido la sexualidad femenina (ejm. Helen Deustch, Marie Langer, Joyce McDougall entre otras), señalando que el requisito básico, para que una niña tenga una identidad sexual y una identidad sexuada, conforme a su $\mathrm{sexo}^{7}$, es un ambiente familiar saludable, donde existe "un modelo heterosexual de una relación afectiva y sensual entre la pareja de padres que se aman, se desean y no tratan de darle al niño la sensación de que es el objeto de su completamiento erótico o narcisista". (McDougall, 1992, pág. 38). Además, la niña tiene necesidad de sentir un padre que valoriza su feminidad y que la madre es el objeto de su amor. Al mismo tiempo, la madre tiene que estimar y respetar al padre, y valorizar la feminidad de su hija, en su vida social y sexual. Gracias a este reconocimiento de la sexualidad, como manifestación natural del ser humano, la niña no corre el riesgo de crecer con una imagen deteriorada o frágil, acerca de su cuerpo o de su sexo ${ }^{8}$, pues es común encontrar en el análisis de pacientes homosexuales mujeres con angustias ligadas a los fantasmas de fragmentación corporal o desintegración.

La vida de Frida Kahlo, en este sentido, fue muy contraria a la imagen deseada. Al parecer la relación de sus padres estuvo al mando de aquella persona a quien Frida llamaba "mi jefe". Su madre, aunque calificada como calculadora, cruel y fanáticamente religiosa, representó también para Frida la mujer activa, inteligente y "el motor del hogar". Tal es así que, al no encontrar Frida un modelo masculino, con quien poder reafirmar su feminidad, deriva todo su interés al proceso de identificación con la madre, en quien puede reconocer una mujer segura y dominante, imagen que necesita para hacer frente a sus temores, temores ${ }^{9}$ engendrados también por esta madre "castradora".

Sabemos que, el nacimiento del erotismo en los niños ocurre, inicialmente, con la madre, la cual es siempre su primer objeto, luego ingresa en la escena el padre ${ }^{10}$. En el caso de Frida, ambas situaciones ocurren sin el desenvolvimiento adecuado; es decir, Frida no tuvo, en primer lugar, el contacto erógeno con su madre ya que ésta ocupaba su tiempo con el cuidado de su otra hija ${ }^{11}$; en segundo lugar, el padre de Frida no representa aquella figura viril que necesitaba para reafirmar su feminidad ${ }^{12}$. Por eso, la manifestación de su erotismo, queda al servicio de otra mujer: la nana, encargada de cuidar a Frida desde aproximadamente los 11 meses. Es con ella, con quien la niña manifiesta toda su sexualidad. Y si sabemos, que los niños en sus fantasías sexuales, incluyen a aquellos objetos que les prodigan placer, pues entonces, no nos quedará

7. Ambos términos son propuestos por McDougall (1992) quien al describir la identidad sexual hace referencia a la convicción que tiene la persona de ser varón o mujer fisiológica y biológicamente hablando y la identidad sexuada se refiere a que la persona asume aquello que es definido como propio de la "masculinidad" o de la "feminidad".

8. Existen numerosas investigaciones (Heilbrun, 1968; Sears, 1965; Lynn, 1962; Wright y Taska, 1966; Rutherford, 1969; ADM, en prensa, etc.) que han encontrado en sus análisis que "las niñas que provienen de hogares con una madre dominante frustrante o indiferente aunque con un padre emocionalmente satisfactorio tienen una experiencia de rol sexual discrepante con su sexo".

9. Imagen, de la autora, que como ya mencionamos anteriormente se deja evidenciar en muchos de sus autoretratos.

10. "Un padre fuerte y lleno de ternura para con su hijita le facilitará abandonar a la madre como objeto amoroso e inclinarse femeninamente hacia él. Una madre feliz con su marido no se verá en la tentación de poner todo su amor insatisfecho en su hija, sobre estimulándola, ni de rechazarla, ni de despreciarla por no ser varón, porque ella misma está contenta con su femineidad. Esto permitirá a su hija identificarse con una madre cariñosa con los hijos y amante con el esposo". (Langer, 1987)

11. La madre, como dice Aulagnier (1975) es la "portavoz" del niño, puesto que es ella quien lo pone en contacto con el mundo del lenguaje. A través de las palabras ayuda a su hijo a atribuir un sentido a las percepciones corporales preverbales y a los fantasmas primitivos; es también ella quien le nombra sus estados afectivos y sus zonas y funciones corporales. De modo que ella ayuda al niño a adquirir una representación nítida de la diferencia entre su cuerpo y su mente, por un lado, y por el otro el cuerpo y la mente maternos. (McDougall, 1992; pag. 118).

12. Bieber en 1962 realizó una investigación con homosexuales y algunas de sus conclusiones fueron: "la mayoría de los padres de éstos homosexuales mantenían relaciones maritales de muy deficiente calidad y casi la mitad de las madres eran esposas dominares que minimizaban a su marido. (en Vara, "La homosexualidad en hombres y mujeres", inédito) 
más que pensar que, era la nana el objeto de estas manifestaciones. Este apego homosexual , se manifiesta en uno de sus poemas:

El milagro vegetal del paisaje de mi cuerpo en tí la naturaleza entera.

Yo la recorro en vuelo que acaricia con mis dedos los redondos cerros, penetran mis manos los umbríos valles en ansias de posesión y me cubre el abrazo de las ramas suaves, verdes y frescas. Yo penetro el sexo de la tierra entera, me abraza su calor

y en mi cuerpo todo roza la frescura de las hojas tiernas. Su rocío es el sudor de amante siempre nuevo. No es amor, ni ternura, ni cariño, es la vida entera, la mía, que encontré al verla en tus manos, en tu boca y en tus senos. Tengo en mi boca el sabor almendra de tus labios. Nuestros mundos no han sido nunca fuera. Sólo un monte conoce las entrañas de otro monte.

Por momentos flota tu presencia como envolviendo todo mi ser en una espera ansiosa de mañana. $Y$ noto que estoy contigo. En este momento lleno aún de sensaciones, tengo mis manos hundidas en naranjas, y mi cuerpo se siente rodeado por tus brazos.

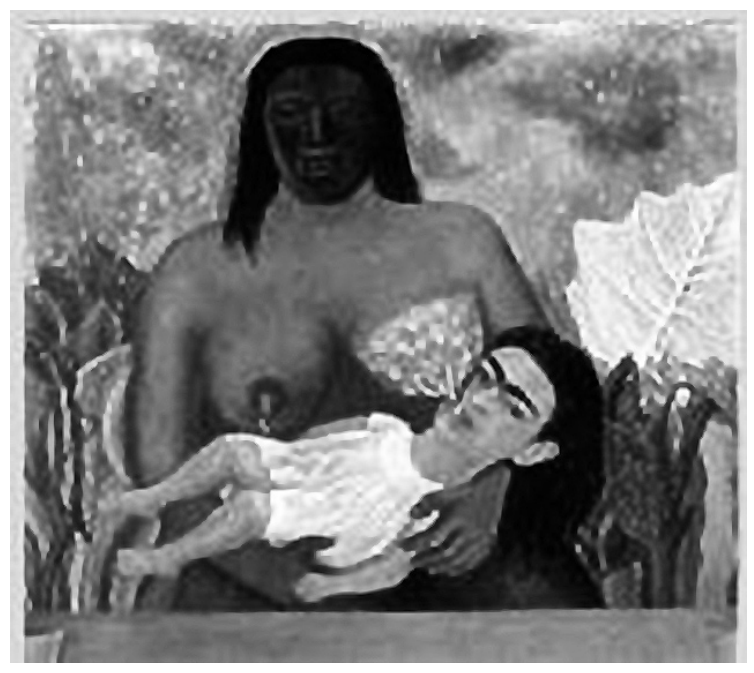

Mi nana y yo, 1937

Pero si sus intereses homosexuales son evidentes a través de su obra ¿cómo entonces llegó a estar casada con un hombre y hasta estar involucrada en una relación heterosexual con el propio Trotsky?. Primero diremos que la homosexualidad como refería Isay (1989): "no sólo se define por la práctica activa, sino por los deseos, los fantasmas y las investiduras que perduran desde la infancia, sean actuales o no" (en McDougall, 1992, pág. 65). Por lo tanto, si bien es cierto que Frida tenía relaciones sexuales con hombres, eso no excluye el interés intenso que tenía por las relaciones homosexuales.

La experiencia clínica demuestra que, son las mujeres homosexuales quienes presentan una angustia muy severa en relación con la actividad heterosexual, pues sienten tal actividad como denigrante y llena de una violencia que las aterra. Pero, la variable que influyó para que éste miedo al "pene" no se materializara en Frida, fue el cuidado de la nana. Así, en palabras de Marie Langer (1987): "Si la primera relación madrehija fue satisfactoria, si la penetración del pezón en la boca de la lactante significó una experiencia feliz para la niña, experiencia que durante el curso de su infancia no fue anulada por un cúmulo de acontecimientos penosos, de adulta no tendrá causas para vivir la penetración del 'pene' de su amado, como un acto sádico y humillante. Su vagina, aceptará el esperma con tanto goce, como aceptó su boca, la leche de su madre". En este caso, aunque no fueron los cuidados de la madre, fueron los de su nana los que le permitieron aquella gratificación oral, que los niños, debido a su 
corta edad y a las tensiones originadas en esa zona, necesitan para su desarrollo normal ${ }^{13}$.

El fracaso de la relación parental dañó profundamente a la niña Frida. El hecho fundamental es que es la madre (o el sustituto de ella), es el primer objeto al que la niña dirige sus impulsos libidinales, luego la niña habrá de desligarse de su madre para dirigirse al padre y crear así el modelo infantil para su elección heterosexual posterior, situación que no pudo concretarse en el caso de Frida, debido a las relaciones que existían entre sus padres. Por ello, la única relación que podría mantener con un hombre, era la misma que había tenido con su progenitor, y ésta fue la admiración que sentía por el arte de su padre, la misma admiración que posiblemente la llevó a ser pareja del también admirado y afamado pintor, Diego Rivera.

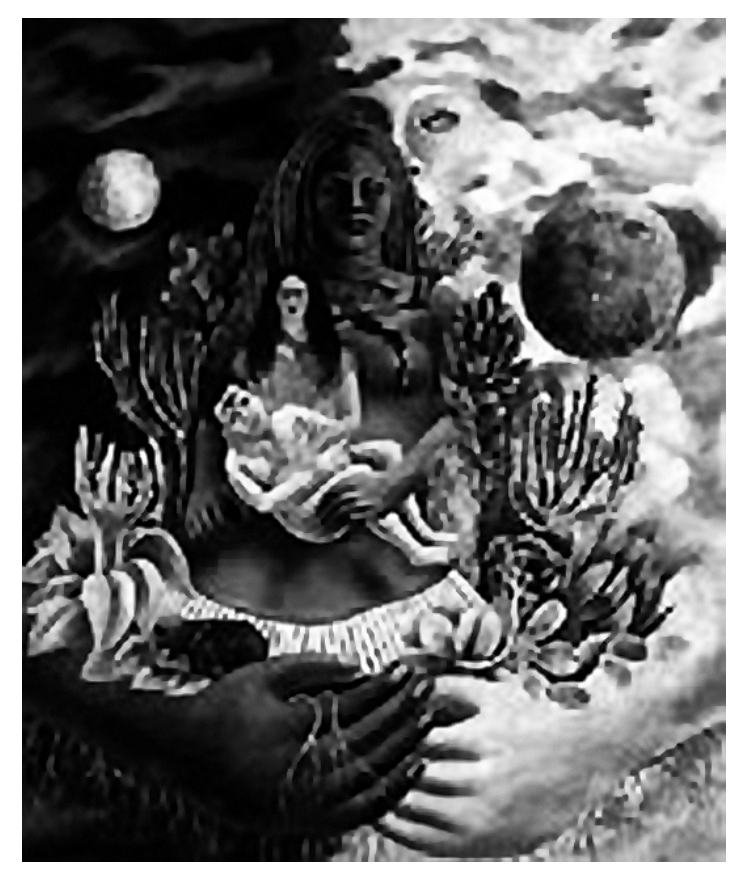

Si hacemos un paralelo entre el cuadro titulado "Mi nana y yo", y observamos a la nana podremos darnos cuenta que la mujer que se encuentra detrás, en este cuadro, de Frida es pintada de la misma forma. Y atrás de ellas se aprecia un rostro de otra mujer, ésta con una mirada vacía, fría y amenazadora que muy bien podría ser la representación de la madre. Y en los brazos de Frida ¿podría acaso ser la representación que tenía de su padre?

\section{Maternidad frustrada}

El embarazo y el parto constituyen un episodio normal de la vida procreativa femenina, pero en la realidad, son muchas las complicaciones que en la actualidad forman ya parte común de estos procesos, me refiero a los dolores y las angustias, los cuales, después de un examen psicológico profundo, nos revelan que provienen de conflictos psicológicos y de identificaciones con otras mujeres ya trastornadas en su feminidad. Tal será el modelo que Frida tendrá de su propia madre.

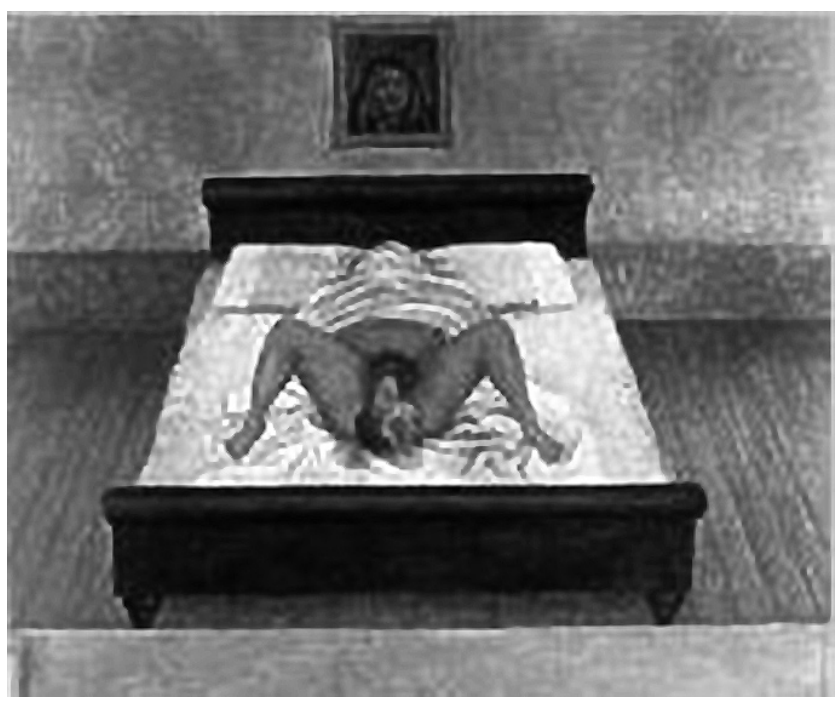

Mi nacimiento, 1932

Este cuadro representa para Frida la forma en como su madre dio a luz su nacimiento, lo curioso de este cuadro es que vemos a una mujer tapada desde los pechos hasta la cabeza al parecer negando este proceso propio de la sexualidad femenina y también todo contacto entre el recién nacido y su madre.

13. Así Tallaferro en su libro Curso básico de psicoanálisis (pág, 148) nos dice: "La succión es la actividad más gratificadora y absorbente, y pese a que muchos la consideran como un simple medio para la ingestión de alimentos, la boca, con sui delicada sensibilidad y sus complejas estructuras musculares, satisface, a través de la succión, importantes necesidades psicológicas. Al tomar el pecho, el niño no sólo llena su estómago sino que adquiere sus primeras sensaciones en conexión con el mundo exterior. Realiza la primera captación factible del mismo. 'Su sentido de seguridad, de satisfacción, placer y éxito están estrechamente vinculados con la actividad bucal', dice la pediatra americana Margaret Ribble, al referirse a la importancia de la etapa oral. Otro aspecto importante de la función de la boca es que aporta a la cabeza y a la cara una mayor provisión de sangre, contribuyendo así al desarrollo progresivo de los músculos faciales y probablemente también del cerebro (Ribble)". 
La causa fundamental por la que una mujer desea tener un hijo, es biológica. Su instinto maternal exige ésta gratificación directa. En la mujer, existe una relación constante, entre los procesos biológicos y psicológicos. Desde la menarquía hasta la menopausia, es decir durante la parte más importante de su vida, se desarrollan en ella procesos biológicos destinados a la maternidad. Por la actuación endocrina de los ovarios, la mucosa de la matriz se prepara, continuamente, para recibir el óvulo fecundado y albergar el feto ${ }^{14}$. En general, se puede decir, que la mujer, aunque utilice medios anticonceptivos y descarte, conscientemente, durante el coito las posibles consecuencias, percibe en su inconsciente una relación constante, entre la aceptación del placer que le ofrece su compañero y la fantasía de un embarazo. Y son las mismas homosexuales, quienes no pudiendo escapar a esta disposición biológica, las que buscan adoptar niños, o se someten a fertilizaciones in-vitro para satisfacer tal necesidad: "El instinto maternal, como parte integrante de la sexualidad femenina, gratifica a través de su realización múltiples deseos de la mujer: Desea un hijo, porque esto significa recuperar a su propia madre a través de la identificación con ésta. También, anhela un hijo para comprobar su propia fertilidad. El deseo de un hijo, puede corresponder a su deseo infantil de regalar un niño a su padre. El feto puede representar para su inconsciente el pene anhelado. Pero en el fondo, el deseo de la mujer de dar a luz un hijo, proviene de su necesidad psicobiológica de desarrollar todas sus capacidades latentes". (Langer, 1987)

¿Qué pudo representar para Frida el accidente de 1925, aquel que le dejó aquella incapacidad para procrear y que es motivo de muchas de sus obras? Es posible, que al sentir la frustración de parte de la madre, por el hecho de no poder cuidarla a causa del nacimiento de su hermana Cristina ${ }^{15}$, Frida sintiera mucho odio hacia su madre, llegando a desear destruir el feto que llevaba dentro. Pero como Freud demostró (y también debido a la "castradora" actitud de la madre), en nuestro inconsciente rige la cruel e inflexible ley del Talión: "ojo por ojo y diente por diente", significando que, como castigo por nuestros malos deseos, esperamos que siempre otra persona ,nos haga lo mismo que le hemos hecho, en la realidad o fantasía. Entonces, es posible que por la fantasía inconsciente de la niñez frente a la madre embarazada, puede deducirse que Frida, adulta ahora, temiera la venganza de su madre; venganza que se hizo evidente a través del accidente que la dejó incapacitada para poder procrear. Y es la propia Frida cuando, al comentar lo que sintió en el accidente de 1925, dijo: "A mí el pasamanos me atravesó como la espada a un toro. Perdí la virginidad", dejándonos claro aquella sensación tan violenta que sintió y que la dejó imposibilitada de gestar; plasmando esto en una pintura, la cual es una de sus obras más representativas: La columna rota (1944), una columna jónica rota en varios lugares, la cual sustituye su columna vertebral.

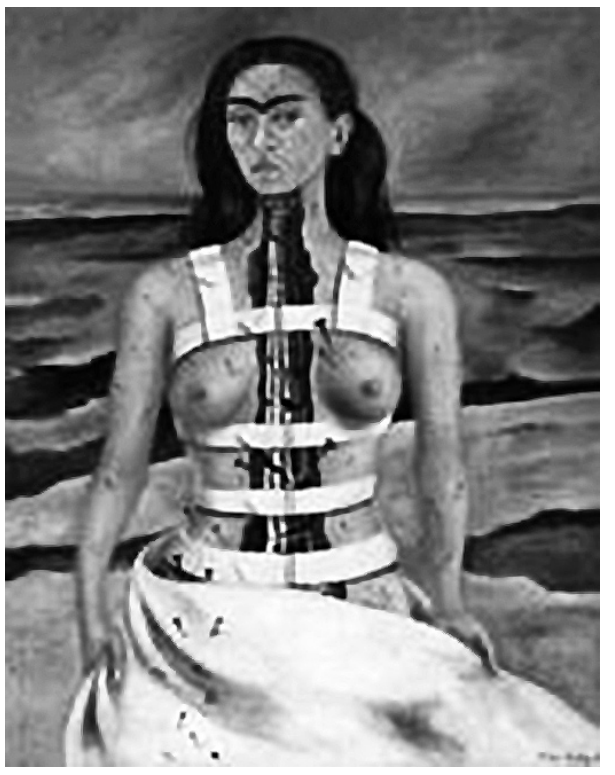

La columna rota (1944)

14. Por ejemplo los estudios de Benedek y Rubenstein, sobre el ciclo sexual de la mujer no dejan lugar a dudas de que ésta preparación biológica se manifiesta en los cambios psicológicos correspondientes. Observaron estos autores un incremento del deseo sexual en la época anterior a la ovulación, es decir de posibilidad máxima de fecundación. En esta época las mujeres estudiadas por ellos experimentaban conscientemente sentimientos de amor y deseaban recibir al compañero, mientras que la tendencia a la impregnación, aunque permanecía habitualmente inconsciente, se expresaba con toda claridad en los sueños. Parece, pues, existir en la mujer un deseo instintivo de ser fecundada y concebir un niño.

15. "Una madre que no prive de cariño y dedicación a su pequeña hija aunque espere un nuevo hijo, no provocará los celos desesperados que suscitará otra, que ocupada y amargada por un nuevo embarazo, rechace a la niña sin darse cuenta a menudo de su actitud hostil". (Langer, 1987) 
Esta pintura nos muestra la destrucción interna de la que Frida ha sido objeto, destrucción que produciría mucha angustia si lo que se siente es que ella ha sido producto de un castigo por antiguos deseos malos.

Asimismo, no se puede deducir que a través de sus pinturas ella expresara el deseo de tener hijos, pues sus pinturas lo único que muestran son las situaciones en las que es víctima de un aborto, más no existe una pintura en la que ella expresa esos deseos maternales a través de retratos con bebés o niños, etc. Parece entonces, que el accidente significó para Frida,, otro castigo inconsciente por aquellos "malos" deseos.

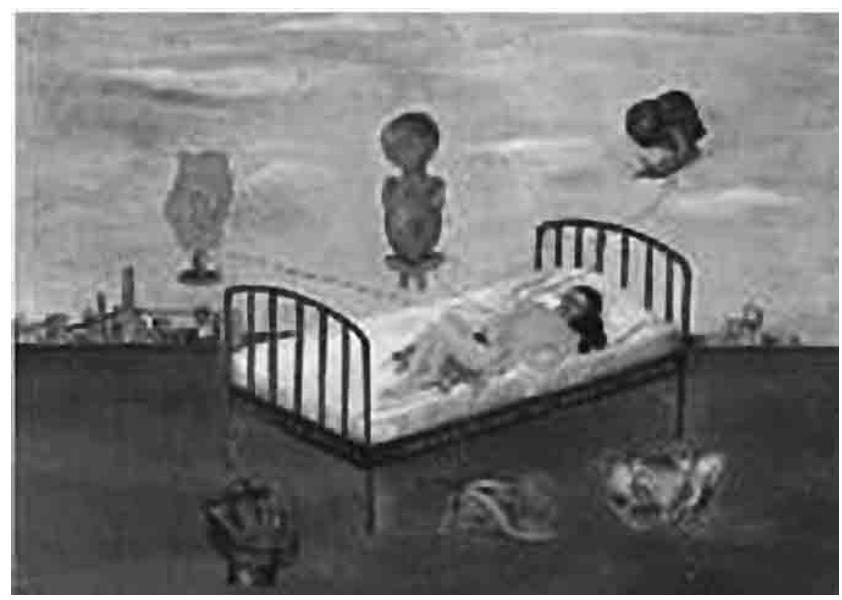

Hospital Henry Ford (1932)

En este cuadro Frida representa una de las tantas situaciones trágicas que pasó en su vida: el aborto. Conscientemente anhelaba tener un hijo pero sus miedos inconscientes fueron más intensos.

\section{CONCLUSIONES}

- El contenido de este ensayo, se ha centrado en la psicogénesis del contenido de la obra de Frida Kahlo, más no en el proceso mental que acompañó a Frida en su creación, esto es, que no hemos incluido el análisis de la represión, la proyección o la resistencia. El análisis se basa, sólo en las descripciones biográficas de la autora, el contenido de sus escritos (poemas) y de sus cuadros pintados.

- La creatividad, se origina en el cuerpo erógeno, reflejando la manera como se representa psíquicamente y como las funciones somáticas han sido estructuradas en la infancia. Pero, la creatividad asociada a la sublimación reviste un problema complejo, pues este debe diferenciarse de la catarsis emocional. Para Frida, la creación artística no parece significar otra cosa que la descarga de sus sentimientos y emociones; especialmente, aquellos que la atormentan. Esta situación, descarta que su obra sea producto de la sublimación, ya que esta última es un proceso que implica más elaboración y no la simple catarsis o descarga emocional.

- Al analizar la obra de Frida encontramos 3 temas, que aparte de ser recurrentes en sus pinturas y poemas, es inevitable someterlos al análisis, para poder entender la personalidad y la obra de la artista. Nos referimos a la masturbación, la homosexualidad y la maternidad.

- El análisis de la situación traumática, no es tan importante como el significado que el sujeto le atribuye, la forma en que actúa, y cómo resiste frente a ella. Todas las experiencias traumáticas en Frida, revivieron las situaciones traumáticas de su infancia, aquellas relacionadas con la “castración” psíquica.

- La situación conyugal de los padres de Frida, la dañaron profundamente. La literatura psicoanalítica, hace referencia a las características que debería tener un hogar, que se precie de ser óptimo y saludable para los niños, y esto es: padres que se amen, se respeten y que valoricen cada manifestación de la sexualidad de los niños, como natural. En el caso de Frida, su madre tuvo a su cargo la dirección del hogar, siendo dominante frente a un padre descrito muchas veces, como una persona taciturna $\mathrm{y}$ callada, dejando de representar la imagen viril que Frida necesitó para reafirmar su feminidad, y construir una identidad heterosexual saludable.

- El nacimiento del erotismo en los niños ocurre, inicialmente, con la madre, la cual es siempre su primer objeto, luego ingresa en la escena el padre. En el caso de Frida, ambas situaciones ocurren sin el desenvolvimiento adecuado; es decir, Frida no tuvo, en primer lugar, el contacto erógeno con su madre ya que ésta ocupaba su tiempo con el cuidado de su otra hija; en 
segundo lugar, el padre de Frida, no representa aquella figura viril que necesitaba para reafirmar su feminidad. Por eso, la manifestación de su erotismo, queda al servicio de la nana, con quien manifiesta toda su sexualidad y, la hace objeto de sus deseos.

- La frustración causada por su madre, por el hecho de no poder cuidarla, a causa del nacimiento de su hermana Cristina, motivó que Frida sintiera mucho odio hacia ella, llegando a desear destruir el feto que llevaba dentro. Pero, por la ley del Talión, teme la venganza de su madre; venganza que se hizo "evidente" a través del accidente que la dejó incapacitada para poder procrear. Para el inconsciente de Frida, la infertilidad causada por el accidente, es un castigo motivado por sus propios deseos destructivos hacia la fertilidad de su madre.

\section{REFERENCIAS}

Deustch, Helen (1960). Psicología de la Mujer. Tomo I y II. Buenos Aires: Losada.
Freud, Sigmund (1895). Estudios sobre la histeria. Madrid: Biblioteca Nueva

Freud, Sigmund (1908). El poeta y los sueños diurnos. Madrid: Biblioteca Nueva

Freud, Sigmund (1910) Un recuerdo infantil de Leonardo da Vinci. Madrid: Biblioteca Nueva

Freud, Sigmund (1915) La vida sexual humana. Madrid: Biblioteca Nueva

Langer, Marie (1987) Maternidad y Sexo. México: Paidós.

McDougall, Joyce (1992) Las mil y un caras de eros. Buenos Aires: Paidós.

Sherman, Julia (1978) Psicología de la Mujer: Una revisión de estudios empíricos. México: Marova

Tallaferro, A. (2010 ) Curso básico de psicoanálisis. Recuperado de: https://mmhaler.files.wordpress. com/2010/06/a_talaferro-curso-bc3a1sicodepsicoanalisis.pdf.

Vara, Arístides (1999) La homosexualidad en hombres y mujeres. El retorno a lo patológico. Lima: Inédito

Fecha de recepción: 27 de octubre de 2014

Fecha de aceptación: 10 de noviembre de 2014 